\title{
CORRIGENDUM
}

\section{Expression of cytokines, growth factors and apoptosis-related signal molecules in chronic pressure ulcer wounds healing}

L Jiang, Y Dai, F Cui, Y Pan, H Zhang, J Xiao and FU Xiaobing

Spinal Cord (2015) 53, 332; doi:10.1038/sc.2015.25

Correction to: Spinal Cord (2014) 52, 145-151; doi:10.1038/ sc.2013.132; published online 3 December 2013

Since the publication of this article, the authors have noticed that the research grant number for the support of the Technical Department of
Zhejiang Province, China, 2008C33044, is incorrect. The correct research grant number is 2012 C 33061 .

The authors apologize for any inconvenience caused. 